\title{
Central Nervous System Involvement Mimicking Multiple Sclerosis in a Patient With Sjogren's Syndrome
}

\author{
İsmail BOYRAZ, Bünyamin KOÇ, Selma YAZICI \\ Department of Physical Medicine and Rehabilitation, Medical Faculty of Abant İzzet Baysal University, Bolu, Turkey
}

Sjogren's syndrome (SS) is a systemic autoimmune disease that can involve both the peripheral nervous systems and central nervous systems (CNS). It is characterized by a lymphocytic infiltration of all exocrine glands. ${ }^{1}$ Neurologic symptoms including transverse myelitis, optic neuritis, stroke-like acute symptoms or several neurological disorders like progressive relapsing remitting attacks mimicking multiple sclerosis (MS) may develop in patients with SS. Herein, we reported a patient who had been treated/followed-up previously with the diagnosis of MS and was diagnosed subsequently with SS.

A 55-year-old male patient was admitted to the neurology outpatient clinic with complaints of weakness and numbness in left leg. Steroid treatment was administered with a diagnosis of MS in 1998, based on the findings of a cranial magnetic resonance imaging. Cerebrospinal fluid examination was normal, except for the slightly elevated protein level and presence of a single oligoclonal band. His complaints recurred one week later following the treatment, and speech disorder developed one year later. The patient suffered two episodes of the disease within one year, and prophylactic interferon beta-1a was initiated. The magnetic resonance imaging in 2005 revealed resolution in the brain lesions and chronic infarctions. In the first physical examination at the initial period of the complaints, he had common paresis and cerebellar functions were impaired. Muscle weakness deteriorated gradually. The diagnosis of primary SS was considered in 2005 upon onset of mouth and eye dryness. Anti-Sjogren syndrome antigen B and other autoimmune antibodies were negative and inflammatory markers were within the normal range. Anti Ro-52 was weakly positive. A salivary test was positive, while the Schirmer and pathergy tests were negative. No sign of vasculitis was detected in the selective cerebral angiography. Sialography was normal and a salivary gland biopsy was compatible with SS score of 3. A skin biopsy revealed ruptured/destructed folliculitis, and therefore we excluded vasculitis. As the patient had dry eyes for at least three months and symptoms of dry mouth for at least three months, unstimulated whole salivary flow, abnormal salivary gland biopsy, and Anti-Ro (+), we have diagnosed the patient as SS according to European diagnostic criteria ${ }^{2}$ and determined CNS involvement of SS mimicking MS.

The incidence of neurological involvement in primary Sjogren's syndrome (pSS) is about $10-60 \%$. The exact pathogenic mechanisms of the neurological involvement are still unknown. Some authors suggested that CNS involvement results from small vessel vasculitis. ${ }^{3}$ The rate of nerve involvement is $20-25 \%$ in SS, $87 \%$ of which can be attributed to peripheral nervous systems involvement. Cerebral involvement is heterogeneous, while CNS involvement may

Received: April 09, 2015 Accepted: June 23, 2015 Published online: July 31, 2015

Correspondence: İsmail Boyraz, MD. Abant İzzet Baysal Üniversitesi Tıp Fakültesi Fiziksel Tıp ve Rehabilitasyon Anabilim Dalı, 14280 Gölköy, Bolu, Turkey. Tel: +90 374 - 2628445 e-mail: boyraz@yahoo.com

@2015 Turkish League Against Rheumatism. All rights reserved. 
sometimes mimic MS.4 Peripheral neuropathy, myositis, seroimmunological disorders and cutaneous vasculitis, which are rarely seen in cases of MS, may indicate "MS-like pSS". 4-6 Cerebrospinal fluid electrophoresis in pSS demonstrates one or two oligoclonal band formation, while multiple bands are seen in MS. Oligoclonal bands may be detected in $90 \%$ of MS patients and in $20-25 \%$ of pSS patients, although these bands may resolve with steroid treatment. ${ }^{1}$

In conclusion, CNS involvement in patients with pSS may mimic some other diseases like MS, as seen in our patient. Clinical, laboratory, and radiological findings should be evaluated and examined carefully for differential diagnosis.

\section{Declaration of conflicting interests}

The authors declared no conflicts of interest with respect to the authorship and/or publication of this article.

\section{Funding}

The authors received no financial support for the research and/or authorship of this article.

\section{REFERENCES}

1. Morgen K, McFarland HF, Pillemer SR. Central nervous system disease in primary Sjogrens syndrome: the role of magnetic resonance imaging. Semin Arthritis Rheum 2004;34:623-30.

2. Sankar V, Noll JL, Brennan MT. Diagnosis of Sjögren's syndrome: American-European and the American College of Rheumatology classification criteria. Oral Maxillofac Surg Clin North Am 2014;26:13-22.

3. Kurne A, Isikay IC, Karlioguz K, Kalyoncu U, Aydin $\mathrm{OF}$, Calguneri $\mathrm{M}$, et al. A clinically isolated syndrome: a challenging entity: multiple sclerosis or collagen tissue disorders: clues for differentiation. J Neurol 2008;255:1625-35.

4. Wise CM, Agudelo CA. Optic neuropathy as an initial manifestation of Sjögren's syndrome. J Rheumatol 1988;15:799-802.

5. Alexander EL, Malinow K, Lejewski JE, Jerdan MS, Provost TT, Alexander GE. Primary Sjögren's syndrome with central nervous system disease mimicking multiple sclerosis. Ann Intern Med 1986;104:323-30.

6. Gümüş $\mathrm{H}$, Akpınar Z. Sjögren syndrome which simulates relapsing remitting multiple sclerosis clinical features: case report. TJN 2013;19:145-7. 